\title{
Can brain impairment be detected by in utero behavioural patterns?
}

\author{
Naoki Horimoto, Takashi Koyanagi, Hirotaka Maeda, Shoji Satoh, Takeshi Takashima, \\ Taketsugu Minami, Hitoo Nakano
}

\begin{abstract}
Fetal behavioural patterns were examined to test whether they could be used to localise sites of brain damage antenatally. Decreased fetal movement, persistent nonreactive fetal heart rate (FHR) pattern, and/or central nervous system malformation were used as indicators of possible neurological impairment. Ten fetuses tested in this way underwent further ultrasound examination observing movement of the extremities, chest wall (breathing), and eye and mouth, and active/quiet FHR patterns. Eight of these 10 fetuses were found on postnatal examination to have a brain impairment. The fetuses having potential in utero brain impairment were divided into four groups: those with (1) lesion sites at, or caudal to, the ponsmedulla that were specifically identified by fetal behaviour, (2) diffuse lesions in the brain which, although resulting in abnormal behaviour, could not be localised by this behaviour, (3) lesions localised in the cerebral hemisphere(s) but with no abnormal behaviour, and (4) temporally abnormal behaviour in utero, finally changing over to a normal pattern with no neonatal neurological abnormality. A screening system for the antenatal assessment of brain impairment is thus proposed.

(Arch Dis Child 1993; 69: 3-8)
\end{abstract}

Gynecology and

Obstetrics, Faculty of

Medicine, Kyushu

University

Naoki Horimoto

Takeshi Takashima

Hitoo Nakano

Maternity and

Perinatal Care Unit,

Kyushi University

Hospital

Takashi Koyanagi

Hirotaka Maeda

Shoji Satoh

Department of Paediatrics, Faculty of Medicine, Kyushu

University

Taketsugu Minami

Correspondence to: Dr Takashi Koyanagi Department of Gynecology and Obstetrics, Faculty of Medicine, Kyushu University 60, Maidashi 3-1-1, Higashi-ku, Fukuoka 812 Japan.

Accepted 9 March 1993 prenatal brain damage. ${ }^{1}$ Naeye et al provided strong evidence that most examples of cerebral palsy were not the result of perinatal asphyxial events in full term infants, but rather the consequence of, usually unpreventable, prenatal intrauterine problems. ${ }^{6}$ The Neurological Collaborative Perinatal Project of the National Institute of Neurological and Communicative Disorders and Stroke reported that birth asphyxia accounted for only $6 \%$ of all cases of cerebral palsy. ${ }^{5}$

Over the past decade, the assessment of in utero behavioural development has been facilitated by the real time ultrasound observation of fetal movements, such as those of the eyes, extremities (arms and legs), breathing, and mouthing. ${ }^{7-13}$

We previously reported three fetuses without central nervous system malformations, who had abnormal behavioural patterns in utero; the neonates were subsequently found to have brain damage. ${ }^{14}$

We have extended our observations to other fetuses by assessing the correlation between intrauterine behavioural patterns and neonatal outcome and determining the extent to which lesion sites in the developing fetal brain could be localised at term. An attempt was also made to initiate an antenatal screening system, to discriminate those fetuses with compromised central nervous system function from the general population.

\section{Methods}

FETAL POPULATION

A total of 1426 singleton full term fetuses, of between 37 and 41 weeks of gestation, were studied during the three year period from January 1988 to February 1991 in the Maternity and Perinatal Care Unit, Kyushu University Hospital.

\section{PRENATAL CARE SYSTEM}

Standard systematic prenatal care was scheduled at intervals of four weeks until 28 weeks, then once every two weeks until the 36 th week, and weekly thereafter. ${ }^{15}$ At each visit fetal anatomy, growth, and amniotic fluid pocket measurements were evaluated using real time ultrasound. ${ }^{16}$ At 30 weeks or more of gestation, all fetuses underwent fetal heart rate (FHR) monitoring for 30-120 minutes, using a cardiotocograph (Toitu MT-810).
INDICATIONS OF POSSIBLE FETAL BRAIN FUNCTION IMPAIRMENT

Fetuses exhibiting any of the following were considered to have potential in utero brain function impairment.

\section{(1) Decrease or lack of fetal movement}

A decrease or lack of fetal movement was defined as the mother reporting fewer fetal 
Table 1 Clinical profile of the 10 cases with suspected impaired central nervous system function

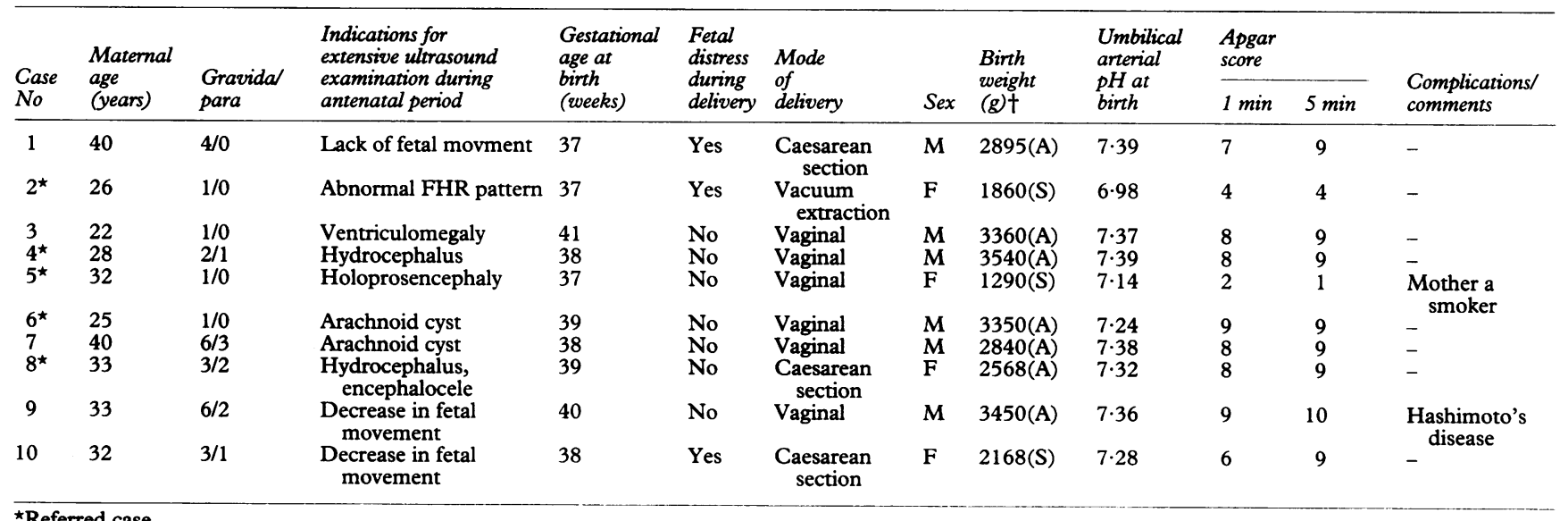

†Appropriate (A) or small (S) for gestational age.

movements than three per 12 hours or experiencing a complete cessation of fetal movement for the same time period. ${ }^{17}$

\section{(2) Persistent non-reactive FHR pattern}

The FHR patterns were categorised by the criteria of Rochard et al ${ }^{18}$ : a 'reactive' FHR pattern was defined as that having a heart rate range between 120 and 160 beats per minute (bpm), a baseline FHR variability of $6 \mathrm{bpm}$ or more, absence of decelerations, and at least two FHR accelerations concurring with fetal movement. A 'non-reactive' FHR pattern consisted of heart rates ranging between 120 and $160 \mathrm{bpm}$ with decreased baseline variability (5 bpm or less) and no accelerations in response to fetal movements. Brown and Patrick have reported that only $1 \%$ of all nonstress tests were found to be non-reactive after 80 minutes, and remained non-reactive until 120 minutes, for a total positive predictive value of $85.7 \%$ at the time of the test. This demonstrates that the increase in observation time does not alter the negative predictive value of a reactive test. ${ }^{19} \mathrm{We}$, therefore, termed a non-reactive FHR pattern continuing for 120 or more minutes as a 'persistent' non-reactive FHR pattern.

\section{(3) Central nervous system malformation}

Of those central nervous system malformations diagnosable using ultrasonography, ${ }^{16}$ holoprosencephaly, encephalocele, arachnoid cyst, porencephaly, agenesis of the corpus callosum, intracranial tumour, and the group of congenital brain diseases accompanying ventriculomegaly, were included in the 'suspicious category' indicating possible fetal brain function impairment.

DEFINITION OF INDICATORS FOR EXTENSIVE EVALUATION OF FETAL BRAIN FUNCTION Of the 1426 screened fetuses, 24 exhibited indications of potential central nervous system impairment before birth: three cases with a decrease or lack of fetal movement, 15 cases showing a persistent non-reactive FHR pattern, and six having central nervous system malfor- mations. Among those having a non-reactive FHR pattern, before any further observations could be made, 12 mothers were excluded from the study with indication of fetal distress and another two due to onset of labour. The remaining 10 mothers gave informed consent and were switched, at 35-36 weeks' gestation, to a programme of extensive observation using real time ultrasound and cardiotocography, specifically designed to assess fetal behaviour (table 1). Real time ultrasound observations were performed (Toshiba SSA-270A with a convex transducer of $3.75 \mathrm{MHz}$ ) with the mother in the semiFowler position, once every 1-2 days. The ultrasound image was stored by video cassette recorder (Sony model VO-9600), together with the simultaneous recording of video frame codes using a frame code generator (Sony model FCG-700). FHR recordings were made 1-3 times a day.

To assess whether brain impairment occurred prenatally, we defined six different behavioural patterns as indicators:

\section{(1) Movement of extremities}

We observed movement in all four extremities in the fetus, for 60 minutes continuously, and defined this movement to be normal when at least one episode of motion, involving extension, flexion, external and internal rotation or abduction and adduction of all extremities occurred. ${ }^{8}$

\section{(2) Breathing movement}

Fetal thoracic and abdominal wall movements were observed using a longitudinal scan in the median plane. One breathing movement was defined as the synchronous movements of the chest wall (inward), the abdominal wall (outward), and diaphragm (downward), followed by their return to the resting positions. ${ }^{20}$

According to the report of Patrick et al no apnoeic intervals were greater than 120 minutes at 34 weeks' gestation onwards. We therefore considered breathing movement as absent when it was not detected for more than 120 minutes' observation by ultrasound. ${ }^{21}$ 


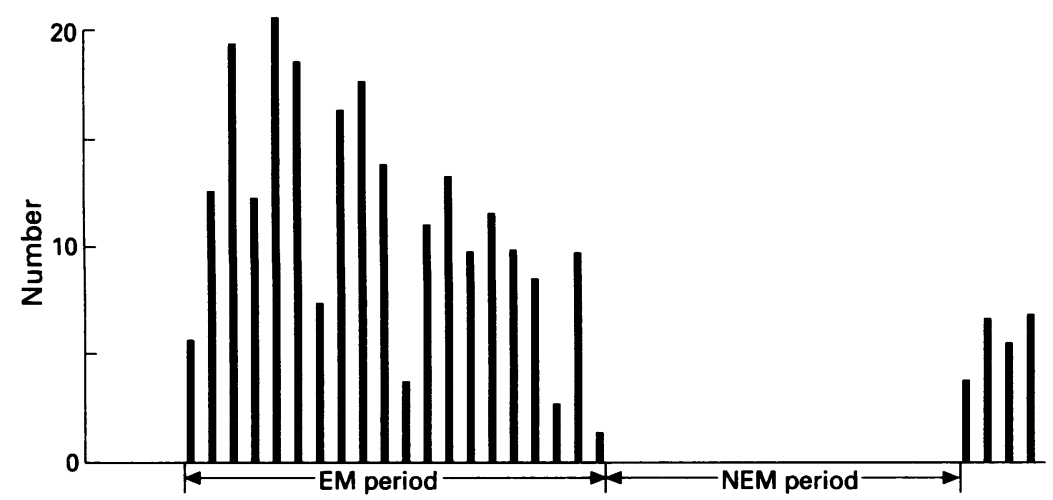

Figure 1 Histogram of eye movements obtained from a fetus at 38 weeks' gestation. The horizontal axis indicates the elapsed time from the start of observation. The vertical axis demonstrates the number of eye movements per one minute epoch. EM=eye movement period, $N E M=$ no eye movement period.

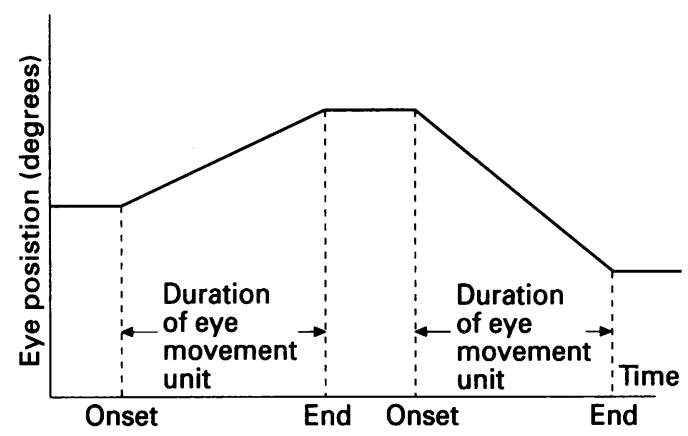

Figure 2 Schema to measure the duration of each eye movement unit. The vertical axis indicates the eye position. The horizontal portions of the solid line show the eye as stationary, while the slanted sections demonstrate eye movement. 'Onset' and 'end' represent the frame codes at the onset and end of eye movement units, respectively.

\section{(3) Alternation of eye movement and no eye movement periods}

The fetal eye closest to the maternal abdominal wall was continuously observed for $60-90$ minutes. A single eye movement was defined as that movement from one position to another, indicated by movement of the pair of dotted echoes originating from the near and far margins of the lens. ${ }^{9} \mathrm{~W}$ ith the total observation period being divided into one minute epochs, we regarded the eye movement and no eye movement periods as those periods sustaining
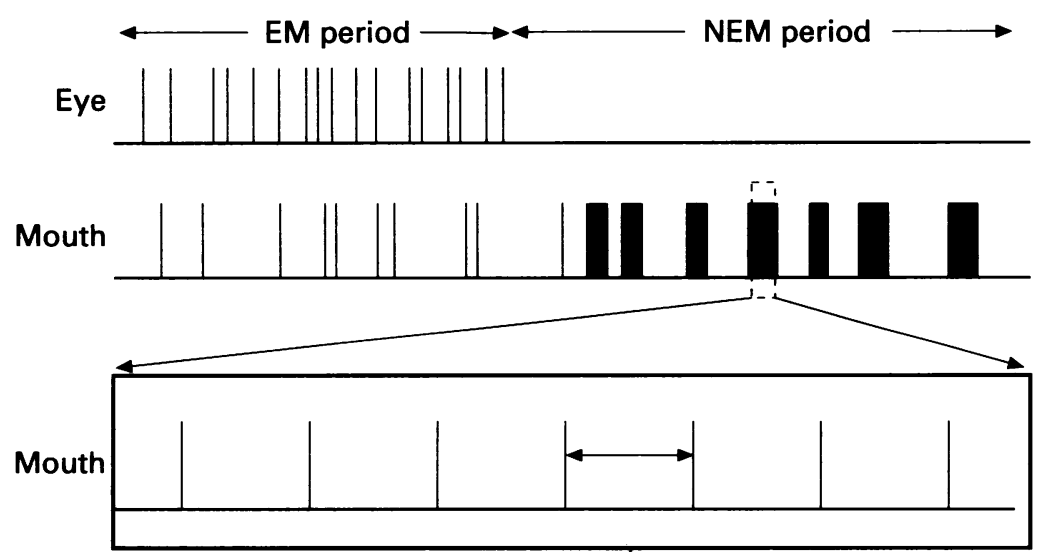

Figure 3 Schema of normal eye and mouthing movement patterns obtained from a term fetus. The horizontal axis indicates the elapsed time from the start of recording. Vertical bars represent one incidence of eye and mouthing movement. Regular mouthing movements are clearly shown on the inset of the horizontal axis in the lower portion of the figure. $E M=$ eye movement period, $N E M=$ no eye movement period. the presence or absence of eye movement, respectively (fig 1). ${ }^{9} 10$ The $25-75 \%$ ranges for the duration of eye movement and no eye movement periods were 2-30 and 2-25 minutes, respectively. ${ }^{13}$ Alternation of eye movement and no eye movement periods was considered to be abnormal when the duration of eye movement and/or no eye movement was out of these ranges.

(4) Eye movement pattern: rapid eye movements and slow eye movements

While replaying the video tapes using the slow motion and frame freezing modes, we measured the duration of each eye movement unit, in seconds, by subtracting the frame code at the onset from that at the end of each eye movement unit (fig 2). Rapid eye movements and slow eye movements were defined as those having durations of less than, and equal to or more than the critical value of 0.76 seconds, respectively, according to our previous report. ${ }^{12}$ The state of rapid eye movement coexisting with slow eye movements was considered to be the normal eye movement pattern.

\section{(5) Concurrence of regular mouthing with the no} eye movement period

Both mouthing movements and eye movements were observed simultaneously on one ultrasound image for 60-90 minutes. We defined one unit of mouthing movement as that action where the mouth opened and returned to a closed position. The interval between two consecutive occurrences of mouthing movement was used as a variable.

Concurrence of regular mouthing movement with the no eye movement period was considered normal when repetitive mouth movements were observed at a regular interval of 300-600 msec during the no eye movement period (fig 3). ${ }^{10}$

\section{(6) Active and quiet phases of FHR pattern}

Following the criteria of Timor-Tritsch et al, ${ }^{22}$ active and quiet FHR patterns are defined as increased long term FHR variability with high baseline heart rate, and decreased long term FHR variability, with low baseline heart rate, respectively. In human fetuses at term, active and quiet phases were reported to last for 30-50 and 20-40 minutes, respectively. When several alternations between active and quiet FHR patterns are observed during an observation period of $120-180$ minutes, the active and quiet FHR pattern was considered to be normal. 1922

\section{ASSESSMENT OF BRAIN IMPAIRMENT AFTER}

\section{BIRTH}

In this study, in order to confirm the existence of brain impairment, all infants underwent a neurological examination on the 28th neonatal day. In the event any abnormal findings were noted, various neurological tests were made, including physical examination, 
Table 2 Correlation between fetal behavioural patterns and postnatal findings

\begin{tabular}{|c|c|c|c|c|c|c|c|c|c|c|}
\hline \multirow[b]{2}{*}{$\begin{array}{l}\text { Case } \\
\text { No }\end{array}$} & \multicolumn{6}{|c|}{ Fetal behavioural patterns } & \multirow[b]{2}{*}{$\begin{array}{l}\text { Postnatal } \\
\text { diagnosis }\end{array}$} & \multirow[b]{2}{*}{$\begin{array}{l}\text { Lesion location } \\
\text { and distribution }\end{array}$} & \multirow[b]{2}{*}{ Age } & \multirow[b]{2}{*}{$\begin{array}{l}\text { Neurological } \\
\text { signs }\end{array}$} \\
\hline & $\begin{array}{l}\text { Movement } \\
\text { of } \\
\text { extremities }\end{array}$ & $\begin{array}{l}\text { Breathing } \\
\text { movement }\end{array}$ & $\begin{array}{l}\text { EM/NEM } \\
\text { period } \\
\text { alternation }\end{array}$ & $\begin{array}{l}\text { Eye } \\
\text { movement } \\
\text { pattern† }\end{array}$ & $\begin{array}{l}\text { Regular } \\
\text { mouthing }\end{array}$ & $\begin{array}{l}\text { Active/resting } \\
\text { FHR pattern }\end{array}$ & & & & \\
\hline $1^{\star}$ & Absent & Present & Normal & Present & Present & Present & $\begin{array}{l}\text { Spinal cord } \\
\text { haemorrhage }\end{array}$ & $\begin{array}{l}\text { Spinal cord } \\
\left(\mathrm{C}_{5-6}\right)\end{array}$ & 20 months & $\begin{array}{l}\text { Quadriplegia, } \\
\text { sensory } \\
\text { disturbance }\end{array}$ \\
\hline $2^{\star}$ & Present & Absent & Absent & Present & $\ddagger$ & Absent & $\begin{array}{l}\text { Möbius' } \\
\text { syndrome with } \\
\text { central hypo- } \\
\text { ventilation }\end{array}$ & Pons-medulla & 3 years & $\begin{array}{l}\text { No spontaneous } \\
\text { respiration, mental } \\
\text { retardation }\end{array}$ \\
\hline $3 *$ & Present & Present & Normal & Present & Absent & Present & Undetermined & $\begin{array}{l}\text { Cerebral white } \\
\text { matter, diffuse }\end{array}$ & 3 years & $\begin{array}{l}\text { Mental retardation } \\
\text { cerebral palsy }\end{array}$ \\
\hline 4 & Present & Present & $\begin{array}{l}\text { Dispropor- } \\
\text { tional }\end{array}$ & Present & Present & Present & $\begin{array}{l}\text { Neuronal migra- } \\
\text { tion abnormality, } \\
\text { hydrocephalus, } \\
\text { cerebellar hypo- } \\
\text { plasia }\end{array}$ & $\begin{array}{l}\text { Cerebral hemi- } \\
\text { sphere, diffuse, } \\
\text { brainstem, } \\
\text { cerebellum }\end{array}$ & 27 months & $\begin{array}{l}\text { Mental retardation } \\
\text { cerebral palsy, } \\
\text { epilepsy }\end{array}$ \\
\hline 5 & Present & Present & Absent & Absent & $\ddagger$ & Absent & $\begin{array}{l}\text { Holoprosen- } \\
\text { cephaly (alobar) }\end{array}$ & Diffuse & $\begin{array}{l}\text { Died shortly } \\
\text { after birth }\end{array}$ & - \\
\hline 6 & Present & Present & Normal & Present & Present & Present & Arachnoid cyst & $\begin{array}{l}\text { Right frontal } \\
\text { lobe }\end{array}$ & 8 months & Not noted \\
\hline 7 & Present & Present & Normal & Present & Present & Present & Arachnoid cyst & $\begin{array}{l}\text { Right } \\
\text { quadrigeminal } \\
\text { cistern to } \\
\text { intrahemispheric } \\
\text { fissure }\end{array}$ & 7 months & Not noted \\
\hline 8 & Present & Present & Normal & Present & Present & Present & $\begin{array}{l}\text { Hydrocephalus, } \\
\text { Encephalocele }\end{array}$ & Occipital lobe & 11 months & Not noted \\
\hline 9 & Present & Present & $\begin{array}{l}\text { Absent- } \\
\text { normal }\end{array}$ & Present & Present & Present & Normal & None & 7 months & Not noted \\
\hline 10 & Present & Present & Normal & $\begin{array}{l}\text { Absent- } \\
\text { present }\end{array}$ & Present & Present & Normal & None & 1 month & Not noted \\
\hline
\end{tabular}

electroencephalography, computed tomography, and magnetic resonance imaging. If the infant died postmortem and/or clinical findings were reviewed and assessed.

\section{Results}

Table 2 shows the summary of the 10 cases with regard to the correlation between the prenatal behavioural patterns and postnatal findings.

In case 1, despite a normal breathing pattern, no movements in any of the four extremities were observed. In case 2 , a lack of breathing movement was noted repeatedly, together with the abnormal finding that the alternation of eye movement and no eye movement periods was undiscriminating. In case 3, the concurrence of regular mouthing with the no eye movement period was not observed. Details of cases 1-3 have been described elsewhere. ${ }^{14}$ In case 4 , although alternating eye movement and no eye movement periods were noted, the duration of these periods was abnormally disproportional, at 23-72 minutes (longer than normal range) and 2-10 minutes (shorter than normal range), respectively. The findings in case 5 demonstrated that only sporadic eye movements existed and, therefore, we could not determine either eye movement/no eye movement period alternation or regular mouthing movements concurrent with the no eye movement period. This case also showed a persistent non-reactive FHR pattern. Repeated ultrasonography revealed that the abnormal patterns observed in cases $1-5$ were persistent. After birth, functional and/or morphological central nervous system abnormalities were detected in cases $1-5$, of which, cases 1 and 2 had localised lesions in the spinal cord (C5-C6) and the pons-medulla, respec- tively, and cases 3-5 were diagnosed as having diffusely spread lesions in the brain.

Cases 6,7 , and 8 showed entirely normal behavioural patterns. Postnatally, however, these cases were found to have localised lesions in the cerebral hemisphere.

In cases 9 and 10, the first extensive examination showed abnormal behavioural patterns in eye movement/no eye movement period alternation and eye movement pattern (rapid/slow eye movement), respectively. However, these findings changed to normal patterns from the second observation onwards. Postnatal physical examinations indicated no neurological abnormalities.

\section{Discussion}

In the present study we focused on detecting brain impairment occurring in utero. Therefore, the neurological outcome was assessed during the early neonatal period in order to avoid the influencing factors acquired during extrauterine life. Accordingly, there may have been some cases that were evaluated as normal at birth but showed mental retardation and/or cerebral palsy a few years later.

The six indicators observed in this study were all considered to be functionally mature, in normal fetuses, from 35-36 weeks' gestation onwards. ${ }^{8-101213192022}$ All cases studied here were within this gestational period, and in eight of the 10 cases suspected as having possible central nervous system impairment, abnormal behavioural patterns were detected repeatedly in every ultrasound examination, providing evidence of existing lesions in the central nervous system during intrauterine life. The remaining two cases, which indicated abnormal patterns in alternation of 
eye movement/no eye movement period and rapid/slow eye movement patterns at first observation, later displaying normal findings from the second to the fourth observation, were found to have no central nervous system lesions after birth. This suggests the possibility of erroneously concluding that an abnormality exists when it really does not, or the existence of transient abnormal brain function.

The fetuses having potential in utero central nervous system impairment at birth could be divided into four groups: those with (1) the lesion sites at, and caudal to the pons-medulla (cases 1-2), which could be identified prenatally according to abnormal behavioural patterns, (2) a diffuse lesion in the brain (cases 3-5), representing behavioural abnormality in utero, although not localising the lesion site, (3) a localised lesion in the cerebral hemisphere(s), for example arachnoid cyst and encephalocele (cases 6-8), indicating no abnormal behaviour during the intrauterine period, and (4) temporally abnormal behaviour in utero (cases 9-10), finally changing over to a normal pattern with no neonatal neurological abnormality. These results suggest that, in the developing human fetus, the central nervous system is not fully functioning and, therefore, in cases where the lesion exists in an, as yet, unfunctioning area, no corresponding behavioural abnormality may be observed.

Applying our system to population screening, 24 cases were regarded as suspicious, of which 10 cases were subjected to further extensive observation. Out of the 10 cases, six suffered from a central nervous system anomaly. The remaining four cases (one selected for abnormal FHR pattern and three for a lack of or decrease in sensation of fetal motion), demonstrated no detectable morphological abnormality in utero by ultrasonography. They did, however, include successfully diagnosed cases having spinal cord haemorrhage and a case of Möbius' syndrome with central hypoventilation. Consequently, it is evident that using the system presented here, five out of 1426 fetuses $(0.35 \%)$ could, in fact, be prenatally diagnosed as having impaired central nervous system functions in utero, which was later confirmed during the neonatal period. The positive predictive value of this system was $71.4 \%$ (five of seven cases).

A clinical system capable of detecting a functional impairment of the central nervous system, in utero, should fulfil the following conditions: it should (1) require only a short observation time, (2) be applicable to all fetuses, (3) have a high sensitivity for identifying brain impairment, and (4) require no special training for the examination. As for the screening system in this study, 20-25 minutes is required to examine each patient, which makes it feasible in daily obstetric practice. In the present study, we selected the following three findings: a lack of or decrease in fetal movement, fetal central nervous system malformation, and abnormal FHR pattern as pointers for examining central nervous system dysfunction.
One case with Möbius' syndrome showed a persistent non-reactive FHR pattern with no signs of fetal distress at 35 weeks of gestation onwards, but had typical fetal distress during delivery leading to vacuum extraction. This fact suggests that the persistent non-reactive pattern, observed in this case, did not indicate hypoxia, but reflected functional impairment of the control centre of fetal heart rate (described elsewhere in detail ${ }^{14}$ ).

In order to discern effectively brain dysfunction in utero, any diagnostic system must contain three elements: a screening procedure for the general population, high detection rate of cases with in utero brain function impairment, and follow up confirmation of impairment after birth. Although the application of fetal behaviour in assessing brain impairment is still in the early stages, ${ }^{23}$ we used this as a prototype for a diagnostic system and could demonstrate its usefulness in clinical practice, especially in cases having underlying neural abnormality without accompanying discernible morphological changes by the current method. However, if we apply the extensive evaluation programme presented in this study to population screening, enormous time will be required to detect abnormal findings as it takes 60-120 minutes to test for each behavioural indicator. To solve this problem and complete the system, after the original accumulation of data from this pilot programme, it is essential to revise the indications of possible central nervous system impairment to include maternal mental retardation, birth weight at and below $2000 \mathrm{~g}$ and/or breech presentation, which are reported to be predictors of cerebral palsy. ${ }^{5}$ Also crucial is the development of an extensive behavioural examination in order to verify brain function more precisely.

We are most grateful to Dr P G Hepper, School of Psychology, The Queen's University of Belfast, for helpful advice. We would also thank Dr T Okudera, Research Institute for Brain and Blood Vessels, Akita, for comments on the manuscript, and L Saza for support with manuscript preparation.

Saza for support with manuscript preparation. Supported by a grant-in-aid for scientific research (No
03454398,05671377 ) from the Ministry of Education, Science 03454398, 05671377) from the Ministry of Education, Science and Culture, and a grant $(3 \mathrm{~A}-4)$ for nervous and me
ders from the Ministry of Health and Welfare, Japan.

1 Ellis WG, Goetzman BW, Lindenberg JA. Neuropathologic documentation of prenatal brain damage. $A m \mathfrak{f} \mathrm{Dis} C$ hild 1988; 142: 858-66.

2 Adams RD, Prod'hom LS, Rabinowicz T. Intrauterine brain death. Acta Neuropath (Berl) 1977; 40: 41-9.

3 Mann LI. Pregnancy events and brain damage. Am $f$ Obstet Gynecol 1986; 155: 6-9.

4 Bejar R, Wozniak P, Allard M, et al. Antenatal origin of neurologic damage in newborn infants. I. Preterm infants. Am 7 Obstet Gynecol 1988; 159: 357-63.

5 Nelson KB, Ellenberg $H$. Antecedents of cerebral palsy. Multivariate analysis of risk. $N$ Engl $f$ Med 1986; 315: 81-6.

6 Naeye RL, Peters EC, Bartholomew M, Landis JR. Origins of cerebral palsy. Am ₹ Dis Child 1989; 143: 1154-61.

7 Birnholz JC. The development of human fetal eye movement patterns. Science 1981; 213: 679-81.

8 de Vries JIP, Visser GHA, Prechtl HFR. The emergence of fetal behaviour. II. Quantitative aspects. Early Hum Dev 1985; 12: 99-120.

9 Inoue $M$, Koyanagi T, Nakahara H, Hara K, Hori E, Nakano $H$. Functional development of human eye movement in utero assessed quantitatively with real-time ultrasound. Am 7 Obstet Gynecol 1986; 155: 170-4.

10 Horimoto N, Koyanagi T, Nagata S, Nakahara H, Nakano $H$. Concurrence of mouthing movement and rapid eye movement/non-rapid eye movement phases with advance in gestation of

11 Hepper PG, Shahidullah S, White R. Fetal handedness? Nature 1990; 347: 431 . 
12 Horimoto N, Koyanagi T, Satoh S, Yoshizato T, Nakano H. Fetal eye movement assessed with real-time ultrasonography: are there rapid and slow eye movements? Am f Obstet Gynecol 1990; 163: 1480-4.

13 Koyanagi T, Horimoto N, Takashima T, Satoh S, Maeda $H$, Nakano $H$. Ontogenesis of ultradian thythm in the human fetus, observed through the alternation of eye movement and no eye movement periods. $\mathcal{F}$ Reprod Infant Psychol 1993 (in press).

14 Koyanagi $\mathrm{T}$, Horimoto $\mathrm{N}$, Maeda $\mathrm{H}$, et al. Abnormal behavioural patterns in the human fetus at term: correlation with lesion sites in the central nervous system after birth. with lesion sites in the central

15 Pritchard JA, MacDonald PC, Gant NF. Prenatal care. Williams Obstetrics. 17th Ed. Norwalk: Appleton and Lange, 1988: 245-66.

16 Romero R, Pilu G, Jeanty P, Ghidini A, Hobbins JC. Prenatal diagnosis of congenital anomalies. Norwalk: Appleton and Lange, 1988.

17 Sadovsky E, Ohel G, Havazeleth H, Stenwell A, Penchas S. The definition and the significance of decreased fetal movements. Acta Obstet Gynecol Scand 1983; 63: 409-13.
18 Rochard F, Schifrin BS, Goupil F, Legrand H, Blottiere J, Sureau C. Nonstressed fetal heart rate monitoring in the antepartum period. Am $\mathcal{f}$ Obstet Gynecol 1976; 126: 699-706.

19 Brown R, Patrick J. The nonstress test: how long is enough? Am $\mathcal{J}$ Obstet Gynecol 1981; 141: 646-51.

20 Trudinger BJ, Knight PC. Fetal age and pattern of human fetal breathing movements. Am $\mathcal{F}$ Obstet Gynecol 1980; 137: 724-8.

21 Patrick J, Campbell K, Carmichael B, Natale R, Richardson $B$. A definition of human fetal apnea and the distribution of fetal apneic intervals during the last ten weeks of pregnancy. Am f Obstet Gynecol 1980; 136: 471-7.

22 Timor-Tritsch IE, Dierker LJ, Hertz RH, Deagan NC, Rosen MG. Studies of antepartum behavioral state in the human fetus at term. Am f Obstet Gynecol 1978; 132: 524-8.

23 Shahidullah S, Hepper PG, Nevin NC. Fetal behaviour and prenatal diagnosis of congenital abnormalities. Obstetrics and Gynaecology Today 1993 (in press). 